\title{
Metadados de preservação digital e os registros digitais arquivísticos
}

\author{
Pedro Felipy Cunha da Silva' \\ Wagner Junqueira de Araújo² \\ Sandra de Albuquerque Siebra ${ }^{3}$
}

\begin{abstract}
Resumo
A intensa utilização de plataformas eletrônicas, especialmente no contexto da pandemia do Covid-19, provocou um aumento significativo dos registros digitais, que documentam os mais variados tipos de atividades pessoais e profissionais. Isto evidenciou a necessidade de descrever e contextualizar estes registros, a fim de contribuir para sua preservação e acesso a longo prazo. Assim, este artigo objetiva fazer uma reflexão acerca das condições que tornam um registro digital, arquivístico e a importância de se considerar os metadados destes registros para a sua preservação. As discussões foram desenvolvidas com base em uma revisão sistemática de literatura, fazendo uso do método PRISMA. Constatou-se que, a partir do instante que o metadado passa a fazer parte do registro digital arquivístico, os cuidados para a gestão desses metadados passam a ser tão importantes quanto os cuidados para a gestão do documento ou registro, isoladamente, já que é impossível realizar a preservação de longo prazo destes materiais sem o efetivo gerenciamento dos metadados que o compõem. Conclui-se que é premente, por parte dos Arquivistas, ampliar a compreensão dos registros digitais arquivísticos como um constructo teórico com desafios conceituais e pragmáticos diferentes, mas não excludentes, daqueles existentes no documento arquivístico digital.
\end{abstract}

\section{Palavras-chave}

Metadados. Preservação digital. Registros digitais arquivísticos.

${ }^{1}$ Universidade Federal da Paraíba iD https://orcid.org/0000-0001-9063-4629 -

E-mail: pedrofelipy@ hotmail.com - João Pessoa, PB - Brasil

${ }^{2}$ Universidade Federal da Paraíba iD https://orcid.org/0000-0002-2301-4996 -

E-mail: wagnerjunqueira.araujo@gmail.com - João Pessoa, PB - Brasil

2 Universidade Federal de Pernambuco iD https://orcid.org/0000-0002-0078-6918 -

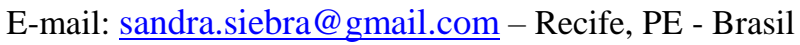

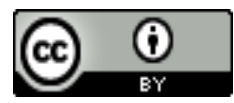

Submetido em: 02/09/2021

Aceito em: Não 18/10/2021

Publicado em: 25/10/2021

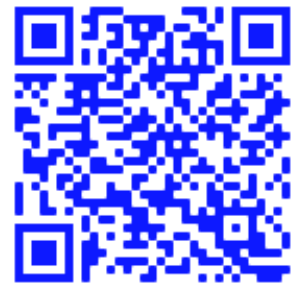




\title{
Digital preservation metadata and archival digital records
}

\begin{abstract}
This article reflects on the concept of digital records, the conditions that make a archival digital record. It is argued that the global coronavirus pandemic has forced the provision of digital services to several services, emphasizing the digital transformation of public and private services, such as remote work and teaching. In this way, it is understood that the use of electronic platforms has caused a significant increase in digital records, which document the most varied types of personal and professional activities, and evidenced the needs of metadata for preservation activities. The discussions were developed based on a systematic literature review, which identified the theoretical contributions to support a study on the relationships between archival digital records and metadata for digital preservation. It was found that, from the moment the metadata becomes part of the archival digital record, care for the management of these metadata becomes as important as care for the management of the document or record, in isolation. Since it is impossible to carry out the long-term preservation of these materials without the effective management of the metadata that compose it. It is urgent, on the part of Archivists, to expand the understanding of archival digital records as a theoretical construct with different conceptual and pragmatic challenges - but not excluding, those existing in the digital archival document.
\end{abstract}

\section{Keywords}

Metadata. Digital preservation. Archival digital records.

\section{Metadatos de preservación digital y registros digitales de archivo}

\section{Resumen}

Este artículo reflexiona sobre el concepto de registro digital de archivo, las condiciones que hacen que un registro digital de archivo. Se argumenta que la pandemia global de coronavirus ha obligado a la prestación de servicios digitales a varios servicios, haciendo énfasis en la transformación digital de los servicios públicos y privados, como el trabajo remoto y la docencia. De esta forma, se entiende que el uso de plataformas electrónicas ha provocado un aumento significativo de los registros digitales, que documentan los más variados tipos de actividades personales y profesionales, y evidencian las necesidades de metadatos para las actividades de preservación. Las discusiones se desarrollaron a partir de una revisión sistemática de la literatura, que identificó las contribuciones teóricas para sustentar un estudio sobre las relaciones entre los registros digitales de archivo y los metadatos para la conservación digital. Se encontró que, desde el momento en que los metadatos pasan a formar parte del registro de archivo digital, el cuidado de la gestión de estos metadatos se vuelve tan importante como el cuidado de la gestión del documento o registro, de forma aislada. Ya que es imposible llevar a cabo la conservación a largo plazo de estos materiales sin la gestión eficaz de los metadatos que lo componen. Es urgente, por parte de los Archiveros, ampliar la comprensión de los registros digitales de archivo como un constructo teórico con diferentes desafíos conceptuales y pragmáticos, pero sin excluir, los existentes en el documento de archivo digital.

\section{Palabras clave}

Metadatos. Preservación digital. Registros digitales de archivo. 


\section{Introdução}

Os impactos da informação digital no cotidiano da sociedade são objeto de estudos há diversos anos (LE COADIC, 1996; LEVY, 1999; CASTELLS, 2002; MATTELART, 2006; ARAÚJO, 2018). O uso da informação nunca foi tão determinante nas relações individuais e de trabalho como na segunda década do século $X X I$. E nesse cenário, as tecnologias digitais de informação e comunicação tornaram-se indispensáveis à realização de inúmeras tarefas de pessoas físicas e jurídicas.

A transformação digital de serviços públicos e privados tornou-se imperativa, sobretudo no contexto da pandemia global do coronavírus, ocorrida a partir de março/2020, que acarretou a necessidade do isolamento social e seus desdobramentos - como o trabalho e ensino remotos, e forçou o início do atendimento de diversos serviços de forma digital. Assim, a utilização de plataformas eletrônicas provocou um aumento significativo das possibilidades de registros digitais, que documentam os mais variados tipos de atividades pessoais e profissionais.

Tal cenário favorece uma reflexão acerca do conceito dos registros digitais, das condições que tornam um registro digital arquivístico, dos elementos que diferenciam um registro digital arquivístico de um documento arquivístico digital, e das ações necessárias para a preservação de registros arquivísticos em ambiente digital. Para isso, é importante definir alguns conceitos.

O Dicionário Brasileiro de Terminologia Arquivística (DBTA), publicado pelo Arquivo Nacional (2005), define documento como "unidade de registro de informações, qualquer que seja o suporte ou formato" (ARQUIVO NACIONAL, 2005, p. 73). Enquanto documento digital é aquele "codificado em dígitos binários, acessível por meio de sistema computacional" (ARQUIVO NACIONAL, 2005, p. 75). Segundo o Glossário da Câmara Técnica de Documentos Eletrônicos (2020, p. 24), documento arquivístico é "Documento produzido (elaborado ou recebido), no curso de uma atividade prática, como instrumento ou resultado de tal atividade, e retido para ação ou referência". E, segundo o mesmo glossário, documento arquivístico digital é o "Documento digital reconhecido e tratado como um documento arquivístico" (p. 25). Outro conceito que se faz relevante no contexto deste trabalho é o de gestão de documentos, que é conceituada como o "conjunto de procedimentos e operações técnicas referentes à produção, tramitação, uso, avaliação e arquivamento de documentos em fase corrente e intermediária, visando sua eliminação ou recolhimento" (ARQUIVO NACIONAL, 2005, p. 100). E para além das definições quanto à instituição, instalações e móvel de guarda, o termo arquivo é definido como o "conjunto de documentos produzidos e acumulados por uma entidade coletiva, pública ou privada, pessoa ou família, no desempenho de suas atividades, independentemente da natureza ou suporte" (ARQUIVO NACIONAL, 2005, p. 27).

Consoante tais concepções, é preciso discorrer sobre a diferença entre a definição de registro digital arquivístico proposta por Rogers (2015) - alicerce teórico 
deste trabalho - e o conceito de documento arquivístico digital, previamente apresentada. Antes, ressalta-se que, para o termo registro, isoladamente, o DBTA (ARQUIVO NACIONAL, 2015) apresenta duas definições. A primeira, relacionada a procedimentos de protocolo, como a "anotação sistemática em livro próprio"; a segunda, com maior proximidade ao tema que se deseja pesquisar, como "unidade de informação logicamente indivisível". Assim

\begin{abstract}
Registros digitais consistem em dados gerados pelo usuário (conteúdo), metadados gerados pelo sistema de identificação de origem e localização, metadados gerados pelo aplicativo que gerencia aparência e desempenho do registro (exemplo: formato de arquivo nativo), metadados gerados pelo aplicativo de descrição dos dados (exemplo: metadados do sistema operacional do sistema de arquivos) e metadados gerados pelo usuário que descrevem os dados (ROGERS, 2015, p. 16, p. 18, tradução nossa). ${ }^{1}$
\end{abstract}

Ao se combinar as definições do Arquivo Nacional (2005) com o conceito de Rogers (2015) acima apresentado, o termo registro digital arquivístico é entendido, para fins deste trabalho, como uma unidade de registro de informações e como um tipo de documento digital que alia conteúdo à descrição e contextualização do mesmo. A aproximação com a definição de documento digital se dá por sua composição em dígitos binários e a necessidade de sistema computacional para sua leitura. Contudo, esse tipo de documento não se limita à forma clássica, uma vez que também considera outros elementos como parte da sua constituição, conforme define Rogers (2015) ao se referir aos metadados.

A condição arquivística dos registros digitais se dará, portanto, quando sua produção e acumulação forem realizadas como prova do desempenho das atividades das pessoas, físicas ou jurídicas, por eles responsáveis. E sua gestão será realizada, de maneira análoga à gestão de documentos e/ou aos procedimentos relativos ao seu ciclo de vida. Deste modo, a gestão arquivística requer além do conhecimento relacionado aos documentos não digitais, compreender e estabelecer procedimentos pertinentes aos arquivos produzidos por meios digitais. Inclusive porque a utilização de ambientes digitais e a consequente produção de registros digitais arquivísticos torna mais complexa a tarefa de gerenciar tais elementos (ROGERS, 2015), dada a multiplicidade de possibilidades de interação e consequente significação pelo usuário (HENNTONEM, 2017).

A diversificação da natureza dos registros digitais é uma realidade e o aumento do seu volume tem sido exponencial nas últimas décadas (KATUU, 2016), de tal maneira que é necessária uma atualização das abordagens para atender às novas demandas de gestão arquivística, necessárias para atuar com essa diversidade

\footnotetext{
${ }^{1}$ No original: "Digital records consist of user-generated data (content), system-generated metadata identifying source and location, application-generated metadata managing the look and performance of the record (e.g., native file format), application-generated metadata describing the data (e.g., file system metadata OS), and usergenerated metadata describing the data".
} 
de acervos em formato digital. Portanto, a importância do arquivo não deve ser percebida apenas no amanhã (FENG, 2017). É preciso reconhecer a contribuição da Arquivologia no presente, para que 0 acesso aos registros digitais no futuro seja possível, pois, a quantidade de registros digitais gerados por meio de sistemas informatizados é cada vez maior, sendo necessário tratamento arquivístico específico, para que a informação possa ser preservada e acessada.

Baron e Thurston (2016) definem a consequência da ausência desse tratamento como "darckarchive", termo que teria a função de transmitir a noção de que o presente e o futuro volumes de informação digital, armazenados em arquivos, não estarão disponíveis a qualquer momento, sem que novas técnicas sejam empregadas por arquivistas. Seria como um "apagão arquivístico" do ambiente digital.

Percebe-se, portanto, a necessidade da existência de um "arquivista digital" (SCHWAITZER, 2018; HENTTONEM, 2017; BARON; THURSTON, 2016), como um profissional com a prerrogativa de enfrentamento dos novos métodos, altamente dependentes de meios automatizados de codificação, classificação e diversas outras tecnologias, de forma que o conteúdo eletrônico possa ser pesquisado e os arquivos digitais possam ser efetivamente acessados a longo prazo por aqueles que necessitarem. E, para isso, é necessário um trabalho conjunto com outros profissionais, de forma que as questões relacionadas à preservação digital destes registros digitais arquivísticos sejam adequadamente tratadas.

O Glossário de Documentos Arquivísticos Digitais (CONARQ, 2020, p. 39) define preservação digital como o "conjunto de ações gerenciais e técnicas exigidas para superar as mudanças tecnológicas e a fragilidade dos suportes, garantindo 0 acesso e a interpretação de documentos digitais pelo tempo que for necessário". E um dos elementos empregados no contexto da preservação digital é a utilização de metadados de preservação.

Desse modo, o presente trabalho busca oferecer uma contribuição para a reflexão da comunidade científica da Arquivologia e da Ciência da Informação, acerca das condições que tornam um registro digital, arquivístico e a importância de se considerar os metadados destes registros para a sua preservação.

Ressalta-se que este artigo é fruto dos resultados de uma pesquisa de mestrado.

\section{Metodologia}

Para realização deste trabalho buscou-se, na literatura, elementos que fundamentassem a conceituação, tipificação e padrões existentes quanto aos metadados de preservação digital para registros digitais arquivísticos. Para isso, 
utilizou-se a metodologia do PRISMA - Preferred Reporting Items for Systematic reviews and Meta-Analyses - composta das fases de identificação, seleção, elegibilidade e inclusão, conforme Moher et al (2009).

Verificou-se que não há consenso quanto ao termo utilizado para se referir à gestão de registros digitais arquivísticos, havendo trabalhos que utilizam digital records management, recordkeeping, digital archival records management, e-records management, eBorn, digital archive material, entre outros termos.

Considerando o objetivo desta pesquisa, a revisão optou por utilizar o termo management of digital records for archives. Sendo assim, o principal critério para inclusão de materiais nessa revisão baseada nas quatro fases do PRISMA foi identificar os conceitos e desafios na gestão de registros digitais para arquivos. Os resultados preliminares são apresentados na tabela 1

Tabela 1 - Resultados da busca

\begin{tabular}{l|l|l|l}
\hline Base de dados & Tipo de publicação & Período & Registros \\
\hline Emerald & Research paper & 2010 a 2019 & 83 \\
\hline Lisa & Artigo & 2010 a 2019 & 165 \\
\hline Scopus & $\begin{array}{l}\text { Artigos de periódicos em } \\
\text { inglês }\end{array}$ & 2010 a 2019 & 106 \\
\hline Web of science & Artigos & 2010 a 2019 & 88 \\
\hline Total & & & 442 \\
\hline
\end{tabular}

Fonte: dados da pesquisa, 2019.

Os metadados foram exportados para os softwares Mendeley e Microsoft Excel. Iniciou-se, portanto, a aplicação do método, conforme resumido na Tabela 2 e descrito a seguir.

Tabela 2 - Resumo da aplicação das fases do PRISMA nesta RSL

\begin{tabular}{|c|c|c|c|c|c|c|c|c|c|c|}
\hline 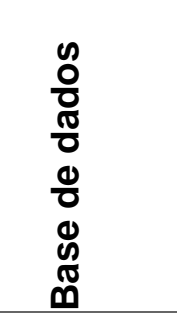 & 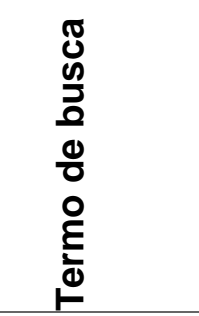 & 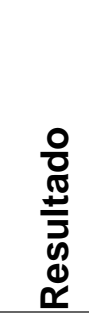 & 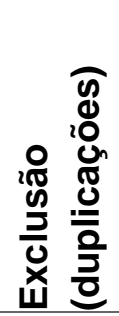 & $\begin{array}{l}\frac{0}{0} \\
\frac{\pi}{0} \\
\overline{\overline{0}} \\
\frac{0}{8} \\
\frac{d}{\mathbf{W}}\end{array}$ & 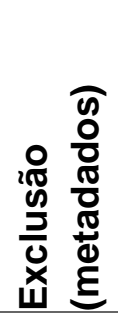 & 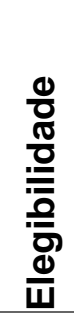 & 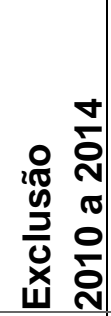 & $\begin{array}{l}\frac{0}{0} \\
\frac{\pi}{0} \\
\text { 음 } \\
\frac{0}{0} \\
\frac{\Phi}{\omega}\end{array}$ & 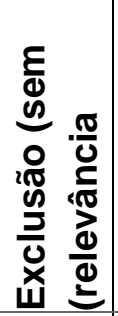 & $\begin{array}{l}\frac{0}{0} \\
\frac{\pi}{0} \\
\overline{\overline{0}} \\
\text { 응 } \\
\frac{\Phi}{\omega}\end{array}$ \\
\hline Emerald & "manage & 83 & 29 & 54 & 38 & $1 \overline{6}$ & $\overline{14}$ & 2 & 1 & 1 \\
\hline Lisa & ment of & 165 & 0 & 165 & 92 & 73 & 13 & 60 & 39 & 21 \\
\hline Scopus & digital & 106 & 12 & 94 & 13 & 81 & 37 & 44 & 23 & 21 \\
\hline $\begin{array}{l}\text { Web of } \\
\text { science }\end{array}$ & $\begin{array}{l}\text { records } \\
\text { for } \\
\text { archives" }\end{array}$ & 88 & 25 & 63 & 48 & 15 & 1 & 14 & 8 & 6 \\
\hline
\end{tabular}




\begin{tabular}{l|l|l|l|l|l|l|l|l|l|l}
\hline Total & & 442 & 66 & 376 & 191 & 185 & 65 & 120 & 71 & 49 \\
\hline
\end{tabular}

Fonte: dados da pesquisa, 2019.

As buscas ocorreram entre as datas de 1 a 3 de junho de 2019 e se restringiram às bases Emerald, Lisa, Scopus e Web of Science. Tais bases foram escolhidas em virtude da relevância que os periódicos indexados possuem para a Ciência da Informação $(\mathrm{Cl})$ e por conterem alto número de trabalhos em seus acervos. Foi recuperado um total de 442 documentos, que após importados para o software Mendeley, continham 66 repetições. Os artigos repetidos foram excluídos e posteriormente foi feita a análise de consistência dos metadados necessários para esta revisão. Constatou-se que 191 publicações não continham o conjunto de metadados desejados, quais sejam: autores, palavras-chave, ano de produção, resumos. Excluídos os artigos sem os metadados, restaram 185 trabalhos a serem analisados, produzidos entre os anos de 2010 a 2019. Considerando que mais de 50\% da produção estava concentrada no período de 2015 a 2019, sendo esse o intervalo mais recente, e a necessidade de diminuição da amostra para fins de eficiência da análise, foram excluídos 65 artigos com data de produção entre 2010 e 2014, restando 120 trabalhos a serem analisados. Após a leitura dos resumos, verificou-se que 71 artigos não estavam diretamente relacionados ao tema investigado, finalizando-se a seleção com 49 publicações consideradas adequadas ao interesse desta pesquisa. Após a finalização das fases de elegibilidade, optou-se por trabalhar com os 49 artigos resultantes da última seleção, a partir dos quais as análises bibliométrica e de conteúdo foram realizadas.

Ressalta-se que outras referências foram incorporadas ao estudo, de forma a complementar conceitos e análises sobre o tema.

\section{Resultados e Discussões}

Os estudos apontam que o acesso aos registros digitais a longo prazo só será possível mediante a adoção de políticas de preservação digital que incluam, dentre outros fatores, normas relacionadas aos metadados (SPENCE et al 2019; RIES, 2018; FORMENTON et al, 2017; RAMALHO et al, 2017; SVÄRD, 2017; LI; SUGIMOTO, 2014; SAYÃO, 2010; CANTARA, 2006; BRINDLEY et al 2004). O que se verificou foi que, ao se estudar sobre registros digitais arquivísticos, a preservação e gestão deste tipo de registro arquivístico está vinculada aos seus metadados.

A preservação digital requer um conjunto de estratégias que devem constituir uma política de preservação digital. São necessárias ações técnicas específicas para os diferentes tipos de tecnologias e suportes utilizados, com destaque para o planejamento preventivo quanto a obsolescência tecnológica. Também deve 
considerar as adequações na cultura organizacional, o alinhamento dos aspectos legais, tais como os direitos autorais e o cumprimento da legislação.

Sobre preservação digital, os fluxos de trabalho devem ser planejados em sintonia com o tipo de material a ser preservado. Por exemplo, nos estudos de Spence et al (2019), sugere-se que objetos digitais provenientes de digitalização devem ser tratados antes dos registros nato digitais. Similarmente a Rogers (2015), acerca da constituição dos registros digitais, Ries (2018) define os registros nato digitais como aqueles constituídos por

[...] objetos digitais, arquivos temporários, metadados e traços fragmentados do processo de criação, espalhado por vários locais do sistema, e que devem ser analisados em relação ao contexto histórico computacional específico, tendo a sua materialidade distribuída no conjunto de hardware, sistema operacional e aplicativo onde foi produzido (RIES, 2018, p. 1 tradução nossa). ${ }^{2}$

Para Svärd (2017), a instituição que deseja preservar o conteúdo dos registros digitais acessível ao longo do tempo, precisa ter um repositório, recursos humanos e financeiros compatíveis com a complexidade que a gestão eficaz do material digital requer. Uma vez que uma política de preservação digital não depende apenas da tecnologia, depende igualmente de recursos e de uma estratégia organizacional alinhada a esse propósito (SPENCE et al, 2017). Estratégia que inclua uma abordagem proativa da informação digital, em que os metadados sejam planejados antes mesmo da criação dos registros digitais (SVÄRD, 2017).

Metadados são considerados a chave para a preservação da informação no ambiente digital, pois facilitam a gestão de longo prazo, e documentam as condições de acesso necessárias para o material digital a ser preservado (BRINDLEY et al, 2004).

Nesse sentido, convém mencionar as principais definições para o termo "metadados" encontradas por esta pesquisa. Para Dappert et al (2013), metadados são informações sobre um objeto necessárias para gerenciá-lo. Na Política de Preservação Digital, produzida pelo Grupo de Trabalho de Preservação Digital da Biblioteca da Universidade de Glasgow,

\begin{abstract}
Metadados são informações adicionais que acompanham o recurso digital para garantir que ele possa ser acessado e compreendido ao longo do tempo, como palavras-chave usadas como tags para permitir uma busca e recuperação precisas. Os exemplos incluem o criador dos dados, a data e hora de criação, o tamanho do arquivo de dados, o tipo de arquivo (.docx, .pdf), etc. (DIGITAL PRESERVATION WORKING GROUP - UNIVERSITY LIBRARY - GLASGOW UNIVERSITY, 2020).
\end{abstract}

\footnotetext{
${ }^{2}$ No original: "[...] the born-digital record, consisting of digital objects, temporary files, metadata, and fragmented traces of the writing process scattered across multiple system locations, has to be analyzed with regard to the specific historical computing context, its distributed materiality ensemble of hardware, operating system, and application".

\begin{tabular}{|l|l|l|l|l}
\hline Rev. Bras. Presev. Digit. / Braz. J. Preserv. Digit. & Campinas, SP & v. 2 & e021003 & 2021 \\
\hline
\end{tabular}
}


Saliente-se que, na literatura, metadados são divididos em categorias ou tipos específicos, a saber:

- Metadados descritivos ou de identificação - visam à pesquisa, recuperação e identificação. Podem conter elementos como, por exemplo, título, autor, assunto e palavras-chave.

- Metadados estruturais - vinculam de forma hierárquica distintos objetos digitais (textos, imagens, áudios etc.) integrantes de um mesmo documento ou recurso informacional.

- Metadados administrativos - dispõem informações que suportam a gerência dos recursos arquivísticos eletrônicos. Incluem de que forma e em que ocasião os recursos foram gerados, espécie de ficheiro ou de arquivo de computador e demais informações técnicas, além dos titulares com direitos ou permissões de acesso.

- Metadados técnicos - especificam os aspectos técnicos dos arquivos e dos seus formatos.

- Metadados de preservação - incluem informações requeridas ao arquivamento e salvaguarda dos objetos digitais ao longo do tempo (FORMENTON et al, 2017, p. 84-85).

Com base nos objetivos já apontados, o recorte utilizado por este trabalho são os metadados de preservação digital. Dessa forma, trataremos dos conceitos que se relacionam com os metadados de preservação, a começar pelo termo "longo prazo" que, para os fins desta pesquisa, será entendido de acordo com a definição da Administração Nacional Norte-Americana de Aeronáutica e Espaço (NASA), como "o tempo suficiente para que haja uma preocupação com a mudança de tecnologia", conforme Sawyer e Reich (2004 apud CANTARA, 2006, p. 40).

Destaque-se que a referida agência americana, por meio do Comitê Consultivo para Sistemas de Informação Espacial (CCSDS), de acordo com Brindley (2004), Cantara (2006) e Sayão (2010), é autora do mais importante modelo de requisitos de preservação de objetos digitais da atualidade, o Reference Model for an Open Archival Information System, mais conhecido como OAIS, que pode ser definido como

[...] uma infraestrutura conceitual que descreve o ambiente, as interfaces externas, os componentes funcionais e os objetos de informação, associados com um sistema responsável pela preservação de longo prazo de materiais digitais (SAYÃO, 2010, p. 13)

O modelo OAIS é composto de um ambiente de produção, um ambiente de gestão e um ambiente de acesso. As informações são transferidas entre os ambientes através de pacotes de informação, conforme pode ser visualizado na ilustração a seguir: 
Figura 1 - Modelo OAIS

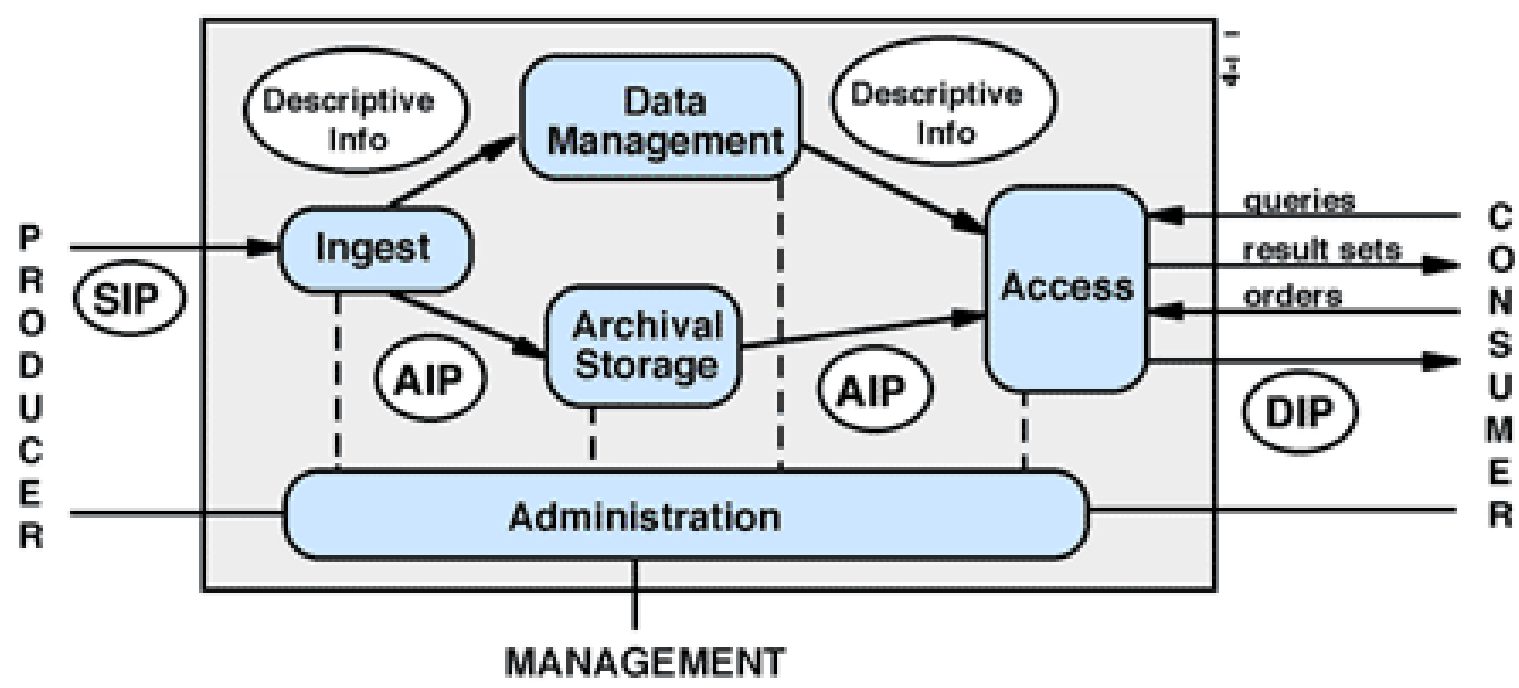

Fonte: dados da pesquisa, 2019.

O autor acrescenta ainda uma relação entre o OAIS, os metadados e a preservação digital:

Quando oferece uma descrição de alto-nível dos tipos de informação que fluem no espaço onde se desenrolam os processos do que chamamos de preservação digital, o OAIS torna evidente o vínculo entre metadados e preservação digital e, dessa forma, reconstrói a ideia de metadados de preservação em bases mais sólidas. Como desdobramento, o modelo de informação OAIS vem constituindo o fundamento comum para a orientação e o desenvolvimento da maioria das iniciativas de metadados de preservação surgidas nos últimos anos (SAYÃO, 2010, p. 15).

Assim, buscando identificar os metadados de preservação necessários para a preservação digital dos registros digitais arquivísticos, mapeou-se na literatura os elementos constitutivos de tais metadados e conceitos que permitam a análise desse tema.

Primeiramente, o termo "preservação digital" pode ser entendido como um processo de acompanhamento do ciclo de vida dos objetos digitais, uma responsabilidade de gestão contínua, começando com a criação do recurso e continuando por um período indefinido (CANTARA, 2006).

Spence et al (2019) compactuam da necessidade de gestão dos objetos digitais antes mesmo da sua criação, como estratégia de preservação digital que garanta que os registros digitais sejam criados conjuntamente com os metadados necessários para a sua interpretação.

O trabalho de Dappert et al (2013) chama a atenção para a necessidade de preservar não apenas o conteúdo, mas a configuração e o ambiente computacional 
necessário para que os registros digitais possam ser acessados ao longo do tempo. Para esse objetivo, desenvolveu-se a iniciativa PREMIS,

[...] uma iniciativa de metadados de preservação digital que integra metadados do ambiente computacional, com metadados de descrição dos objetos, eventos, agentes, e declarações de direitos em um nível direcionado a repositórios OAIS. Com um nível mais abrangente, incorporando uma abordagem de todo o ciclo de vida, o modelo conceitual do domínio da preservação digital (DAPPERT et al, 2013, p. 108).

O PREMIS pode ser entendido como uma aplicação do modelo OAIS, constituído dos metadados necessários para o processo de preservação digital. $\mathrm{O}$ PREMIS estabelece cinco entidades: Environment (Suporte), Object (Objeto), Event (Evento), Agent (Agente) e Rights Statement (Declaração de direitos). De acordo com ARAKAKI et al (2019, p. 9) Suportes são "entidades intelectuais capturadas e preservadas no repositório como Representações, Arquivos e / ou Bitstreams. São também tecnologias (software ou hardware) de um Objeto Digital de alguma forma (por exemplo, renderização ou execução)". O Objeto (ou Objeto Digital) "uma unidade discreta de informações sujeita a preservação digital e usado como parte do processo de preservação." Evento é "uma ação que envolve ou afeta pelo menos um objeto ou agente associado ou conhecido". Agente "uma pessoa, organização ou programa / sistema de software associado a eventos na vida de um objeto ou com direitos associados a um objeto." E a Declaração de direitos é " a afirmação de um ou mais direitos ou permissões pertencentes a um objeto e / ou agente."

Os metadados de preservação podem ser definidos como a informação (incluindo-se os diversos tipos de metadados) que apoia e documenta a preservação de longo prazo bem sucedida de materiais digitais (DAY, 2003; DAPPERT et al, 2013; SAYÃO, 2010), ao passo que as funções destes metadados de preservação podem ser descritas como:

- Registro do histórico, do hardware, software e outras dependências técnicas, das estruturas e das mudanças (de custódia legal e física ou de natureza tecnológica, social etc.) suportadas pelos recursos/objetos digitais, no decurso de todo o seu ciclo de vida (isto é, criação, seleção e descarte, identificação persistente, descrição e acesso, armazenamento e preservação).

- Documentação das tomadas de decisão e atos de preservação, dos métodos de preservação e seus resultados, das ações de gestão de coleções e direitos, além dos próprios metadados, de modo a apoiar os processos ou as iniciativas correntes e vindouras de preservação digital.

- Suporte à descoberta, localização, recuperação, referência única e persistente, preservação, acesso, utilização, comprovação de autenticidade e integridade, bem como gestão de direitos de propriedade intelectual de objetos arquivísticos e museológicos digitais ou eletrônicos.

- Assistência à uma gerência ideal dos objetos digitais, dos sistemas de informação (registros de correspondência e de documentos, registros de funcionamento dos sistemas e seus acessos por intermédio de práticas de auditorias mantidas pelos serviços de TIC, por exemplo), da comunidade usuária e das funcionalidades a serem oferecidas (FORMENTON et al, 2017, p. 85). 
Em complemento, Sayão (2010) estabelece cinco categorias de informação baseadas em Lavoie e Gartner (2005), que devem ser traduzidas pelos metadados de preservação:

1) proveniência - os metadados de preservação devem registrar informações sobre a história do objeto desde sua origem, traçando a sua cadeia de custódia e de propriedade;

2) autenticidade - os metadados de preservação devem incluir informações suficientes para validar que o objeto é de fato o que diz ser e que não sofreu alterações - intencionais ou não - não documentadas;

3) atividades de preservação - os metadados de preservação devem documentar as ações tomadas ao longo do tempo para preservar o objeto digital e as consequências dessas ações sobre aparência, usabilidade e funcionalidades do objeto;

4) ambiente técnico - os metadados de preservação devem descrever as dependências técnicas necessárias para a apresentação e uso dos objetos digitais, tais como hardware, sistema operacional e software de aplicação;

5) gestão de direitos - os metadados de preservação devem registrar todos os itens relacionados às questões de propriedade intelectual que limitem as ações de preservação, de disseminação e uso por parte de usuários de hoje e do futuro (LAVOIE; GARTNER, 2005 apud SAYÃO, 2010, p. 11-12).

Os estudos de Sayão (2010), Cantara (2006), Brindley (2004) e Day (2001) informam que o pressuposto básico do OAIS é que um recurso de informação tenha dois componentes: o objeto que precisa ser preservado e as informações que tornem o objeto compreensível para os usuários do repositório/arquivo. Ou seja, todo objeto de informação é composto por objeto de dados (físico ou digital) e por uma informação de representação que permite a completa interpretação dos dados em informações com significado. É nesse sentido que o modelo OAIS estabelece três tipos de pacote de informação, definidos como: pacote de informação de submissão, constituído do conteúdo e metadados elaborados pelo produtor no momento do depósito no repositório; pacote de informação de armazenamento, constituído pelo conteúdo e metadados efetivamente armazenados e gerenciados pelo repositório por longo prazo; e pacote de informação de disseminação, formado pelo conteúdo e metadados entregues pelo repositório em resposta a uma requisição de acesso demandada pelo usuário (DAPPERT et al 2013; SAYÃO, 2010; CANTARA, 2006).

Para o fim de preservação de longo prazo, conforme Sayão (2010, p. 17), o pacote objeto desta pesquisa é o pacote de informação de armazenamento, que se constitui de vários tipos de informação, quais sejam:

Informação de conteúdo - é a informação que o repositório tem obrigação de preservar, inclui a informação de representação, que são informações necessárias à apresentação e à interpretação da cadeia de bits que constituem o objeto armazenado como informação com significado para uma determinada comunidade alvo;

Informação de descrição de preservação - informação que apoia e documenta a preservação dos objetos arquivados no repositório;

Informação de empacotamento - informação que agrega todos os componentes de um pacote de informação - conteúdo e seus metadados numa única unidade lógica;

Informação descritiva - informação que apoia o usuário na descoberta e na recuperação de objetos armazenados no repositório (CCSDS, 2002, p. 2-6). 
Observa-se que, para além das categorias de informação apontadas anteriormente, o CCSDS estabeleceu um detalhamento da informação de descrição de preservação em quatro grupos distintos de dados, definidos em:

\begin{abstract}
Informação de referência - tem origem na necessidade de identificar e de localizar um objeto ao longo do tempo para manter a sua integridade; a referência identifica ou, se necessário, descreve um ou mais mecanismos usados para assinalar identificadores aos objetos armazenados, de forma que eles possam ser identificados inequivocamente interna e externamente ao repositório. Por exemplo, um identificador local (um número de chamada) e um DOI ou um ISBN; pode incluir ainda informações que descrevem o objeto, por exemplo, um resumo.

Informações de contexto - está relacionado ao fato de que muitos objetos não podem ser adequadamente interpretados sem a compreensão do seu contexto; informação que documenta o relacionamento do objeto armazenado e seu ambiente; isso inclui a motivação da criação do objeto e como ela se relaciona com outros conteúdos; circunscreve as dependências técnicas - hardware, software, linkage, etc. - inclui ainda modo de distribuição, por exemplo, via rede.

Informação de proveniência - refere-se ao princípio de que parte da integridade de um objeto depende da sua história; informação que documenta a história do objeto armazenado; pode incluir informações sobre sua fonte ou origem, sua cadeia de custódia; registra também as ações de preservação sofridas pelo objeto e seus efeitos, por exemplo: as migrações efetuadas.

Informação de fixidez - refere-se a qualquer informação que documenta mecanismos particulares de autenticação usados para assegurar que o objeto armazenado não sofreu nenhuma alteração não documentada, e que sua integridade não foi comprometida, por exemplo, assinaturas digitais e checksums (CCSDS, 2002, p.4-28).
\end{abstract}

Infere-se, com base em Sayão (2010, p. 18), que esses grupos de informação - que formam as bases das principais estruturas de metadados de preservação "constituem a descrição mais geral de metadados necessários para instruir a preservação de longo prazo e o uso de materiais digitais".

Observa-se, porém, que o trabalho de Sayão (2010) apontou preservação de tecnologia, emulação, migração e encapsulamento como estratégias de preservação digital, sem mencionar os metadados. Enquanto que Adu e Ngulube (2016), além das opções já apresentadas, também consideram os metadados, juntamente com repositórios confiáveis e computação em nuvem, como parte das estratégias de preservação digital. Contudo Moss et al. (2018) alertam que metadados sozinhos não constituem uma solução por si, pois atribuir ao usuário a responsabilidade por criar e acrescentar os metadados adicionais é irracional.

Conforme o trabalho de Allan (2014; 2015), a designação para a atribuição de metadados por parte dos produtores dos registros não está funcionando de forma eficiente nos países que já implantaram tal política. Para os autores das duas investigações produzidas pelo Arquivo Nacional do Reino Unido, junto aos órgãos públicos a ele vinculados, os resultados demonstraram que não se pode esperar que gestores ajam como arquivistas e saibam avaliar o que deve ser preservado e o que não deve no ambiente digital. 
Rogers (2015), que conceitua registros digitais arquivísticos com base nos metadados, destaca que são os metadados que tem a tarefa de subsidiar as ações de gestão e preservação dos registros digitais. Para a autora, utilizando os princípios diplomáticos básicos, os registros digitais podem ser identificados por meio da definição de quais metadados devem ser capturados, gerenciados e preservados. De fato, arquivistas americanos já trabalham em requisitos para gestão de registros digitais desde o final do século XX. Porém, a literatura aponta para uma necessidade obrigatória de atenção aos metadados no trabalho de gestão e preservação dos registros digitais arquivísticos, embora ainda se tenha muito a fazer nesse sentido. De acordo com o trabalho de Bantin (1998), ao analisar o sistema de registros de uma universidade, foram identificados como sendo os principais problemas:

1) a falta de procedimentos, mecanismos e prazos para garantir que os metadados permaneçam unidos ou vinculados ao registro; 2) a falta de mecanismos definidos para migração (em oposição a backups simples) de registros; e 3) a falta de procedimentos para garantir que os registros permaneçam invioláveis ao longo do tempo (BANTIN, 1998, p. 362).

Além disso, de acordo com Hofman et al. (2017), as pessoas e organizações provavelmente não vão parar de "confiar" seus registros a provedores em nuvem, em que a perda do contexto desses dados configura-se como um problema. De acordo com os autores, os riscos envolvidos no armazenamento não controlado em nuvem precisam ser mitigados e uma solução possível seria o controle de privacidade no nível do registro. No entanto, essa solução exigirá reformular o modelo de privacidade atual de um modelo focado em "informações" privadas - um termo amplo que engloba dados e registros de ambos - para um focado nos desafios coexistentes de dados privados (que sem dúvida existem fora dos registros), bem como de registros privados (HOFMAN et al., 2017, p. 10), o que indica a necessidade de se desenvolver um novo modelo gerencial para as cadeias de custódia, a fim de garantir a confiabilidade dos registros digitais arquivísticos.

Nesse contexto, Guo (2016), tratou sobre o papel do arquivo, enquanto instituição de custódia, na questão da confiabilidade de registros digitais. $\mathrm{O}$ autor descreve a atuação do arquivo público como terceiro confiável neutro e imparcial para depósito de registros de instituições públicas e privadas. Guo (2016, p. 13) pontua três principais dificuldades: "a aplicabilidade dos métodos de encapsulamento, a exigência de gerenciar dados estruturados de forma fixa e o grande volume de dados envolvidos". Entretanto, essa expansão no papel do arquivo trouxe, segundo o autor, "novas questões para os arquivistas quanto ao relacionamento entre arquivos públicos e registros privados, e o relacionamento entre arquivos públicos e serviços de armazenamento comercial".

Diante do exposto, é possível afirmar que todas as iniciativas de preservação digital presentes neste estudo sobre os registros digitais arquivísticos indicam sua relação com os metadados, sejam como estratégia ou parte da estratégia de

\begin{tabular}{|l|l|l|l|l}
\hline Rev. Bras. Presev. Digit. / Braz. J. Preserv. Digit. & Campinas, SP & v. 2 & e021003 & 2021 \\
\hline
\end{tabular}


preservação, como necessária para garantir o acesso às informações criadas em ambientes digitais. Há, ainda, uma tendência pela adoção de esquemas padronizados de metadados (FORMETON et al., 2017), que diminuam as barreiras terminológicas e facilitem a interoperabilidade dos repositórios, com o objetivo comum de garantir o acesso pleno aos objetos digitais agora e no futuro.

\section{Considerações}

Este trabalho buscou oferecer uma oportunidade de reflexão sobre a necessidade de preservação dos registros digitais arquivísticos, e das suas relações com os metadados. E, a partir das leituras realizadas foi possível entender que o registro digital arquivístico é composto por elementos constitutivos mais amplos do que o documento arquivístico digital, a saber, os diferentes tipos de metadados que precisam ser incorporados ao registro para que ele faça sentido, tanto no aspecto físico, quanto lógico, como conceitual.

A partir da compreensão de que o metadado é parte constitutiva do registro digital arquivístico, o cuidado para a gestão desses metadados passa a ser tão importante quanto os cuidados para a gestão do documento ou registro, isoladamente. Já que é impossível realizar a preservação de longo prazo destes materiais sem o efetivo gerenciamento dos metadados que os compõem.

Observa-se que o conceito de registro digital arquivístico ainda precisa de outras reflexões que o esmiúcem e ampliem. Porém, o estudo realizado até aqui nos leva à compreensão de que o registro digital arquivístico se caracteriza como uma proposta conceitual mais ampla do que o documento arquivístico digital (ACKER, 2019; RIES, 2018; ROGERS, 2015), pois ressignifica os limites do que é considerando relevante para a preservação dos requisitos arquivísticos dos documentos em ambiente digital, com destaque para os metadados.

Nesse sentido, o aumento exponencial da produção e a assustadora diversificação dos registros em ambiente digital (KATUU, 2016), aliados às novas possibilidades de interação, e de significação (HENNTONEM, 2017), tornam muito mais complexa a atividade de gestão dos registros digitais arquivísticos (ROGERS, 2015). Assim, Baron e Thurston (2016) sugerem que, se não empregarmos novas técnicas arquivísticas à informação contida nos registros digitais arquivísticos produzidos no presente, eles podem não estar disponíveis ou acessíveis no futuro.

Por isto, é premente, por parte dos Arquivistas, ampliar a compreensão dos registros digitais arquivísticos como um constructo teórico com desafios conceituais e pragmáticos diferentes - mas não excludentes, daqueles existentes no documento arquivístico digital (ACKER, 2019; RIES, 2018; ROGERS, 2015). 
Essa compreensão passa, dentre outros elementos, pela incorporação do metadado como conceito-chave (BRINDLEY et al., 2004), sem o qual não se pode falar em preservação digital de registros digitais arquivísticos. Os metadados precisam considerar o aspecto arquivístico dos registros digitais, mas, não apenas isso, precisam também contemplar elementos personalizados de descrição dos diferentes tipos de registros existentes nos acervos digitais, tais como os registros digitalizados, natodigitais e híbridos, além daqueles que estão surgindo e não se encaixam nessas classificações.

Para isso, surge a necessidade de um Arquivista Digital, que além de dominar todos os conceitos clássicos da Arquivologia, compreenda a importância dos metadados sem perder de vista a relevância de repositórios digitais arquivísticos confiáveis - agora parte do acervo, e que traz os desafios pertinentes à sua adequada gestão. Esse profissional - o Arquivista Digital - precisa trabalhar em conjunto com os profissionais de tecnologia da informação, e ainda absorver a necessidade contínua de gestão do ciclo de vida dos objetos digitais, que constituem o acervo sob sua responsabilidade, para garantir que a preservação digital de longo prazo aconteça. Assim, para gerir tal material, é preciso entender quais são os componentes dos objetos de informação, a saber: o objeto em si, e as informações que tornam o objeto compreensível - para software e hardware (DAPPERT et al, 2013).

Em suma, precisa-se de um olhar mais amplo para os registros digitais arquivísticos, que se preocupe não apenas com a descrição do seu conteúdo, mas também com os metadados de descrição das suas configurações e do ambiente computacional em que foram criados.

Diante da disrupção tecnológica a qual estão submetidas todas as áreas do conhecimento - incluindo a Arquivologia, os novos elementos presentes nas inúmeras possibilidades de documentar as ações, também devem ser repensados pela comunidade científica como partes, ou não, de seu escopo.

Acredita-se que essas medidas são o início de um processo de amadurecimento da gestão de documentos arquivísticos em ambiente digital. Pois é necessário entender que os registros digitais arquivísticos são uma realidade, são documentos gerados por diferentes softwares, sistemas e plataformas tecnológicas durantes as atividades cotidianas de pessoas e organizações. Estes documentos não possuem um formato fixo, mas são flexíveis e podem variar dependendo das ferramentas, ou da interface de acesso. Porém, o que não pode variar é a informação neles contidas, neste ponto é fundamental a definição dos metadados que venham garantir a autenticidade, confiabilidade, integridade e os demais requisitos de um documento arquivístico. Que, também, deverá contemplar a reflexão sobre normas ou padrões de metadados específicos para registros digitais arquivísticos, e a diminuição da assimetria terminológica arquivística, principalmente quanto aos registros e documentos em ambientes digitais.

\begin{tabular}{|l|l|l|l|l}
\hline Rev. Bras. Presev. Digit. / Braz. J. Preserv. Digit. & Campinas, SP & v. 2 & e021003 & 2021 \\
\hline
\end{tabular}




\section{Referências}

ACKER, A. Quando é um registro? Estrutura de pesquisa para localização de registros eletrônicos na infraestrutura. GILLILAND, A. J.; MCKEMISH, S.; LAU, A. J. (org.). Pesquisa no multiverso arquivístico. Trad. de Ana C. Rodrigues. Salvador: 9Bravos, 2019.

ADU, K. K.; NGULUBE, P. Preserving the digital heritage of public institutions in Ghana in the wake of electronic government. LIBRARY HI TECH, ENGLAND, v. 34, n. 4, p. 748-763, 2016. Disponível em: https://doi.org/10.1108/LHT-07-2016-0077. Acesso em: 07 ago. 2021.

ARAKAKI, F. A.; ALVES, R. C. V.; SANTOS, P. L. V. A. C. Preservação digital e proveniência: interseções entre premis e o prov. Encontro Nacional de Pesquisa em Ciência da Informação, n. XX ENANCIB, 2019. Disponível em: http://hdl.handle.net/20.500.11959/brapci/122805. Acesso em: 23 out. 2021.

ARAÚJO, C. A. A. O que é ciência da informação. Belo Horizonte: KMA, 2018. ARQUIVO NACIONAL (Brasil). Dicionário Brasileiro de Terminologia Arquivística. Rio de Janeiro: Arquivo Nacional, 2005.

BARON, J. R.; THURSTON, A. What lessons can be learned from the US archivist's digital mandate for 2019 and is there potential for applying them in lower resource countries? Records Management Journal, [s.I.], v. 26, n² 2, p. 206-217, 2016.

BRINDLEY, G.; MUIR, A.; PROBETS, S. Provision of digital preservation metadata: A role for ONIX? Program, [S. I.], v. 38, n. 4, p. 240-250, 2004. Disponível em: https://doi.org/10.1108/00330330410699883. Acesso em: 07 ago. 2021.

CÂMARA TÉCNICA DE DOCUMENTOS ELETRÔNICOS (CTDE). Glossário. Disponível em: http://www.documentoseletronicos.arquivonacional.gov.br/media/2008ctdeglossariov 5.pdf. Acesso em: 12 ago. 2021.

CANTARA, L. Long-term preservation of digital humanities scholarship. OCLC Systems and Services, [S. I.], v. 22, n. 1, p. 38-42, 2006. Disponível em: https://doi.org/10.1108/10650750610640793. Acesso em: 07 ago. 2021.

CASTELLS, M. A sociedade em rede: a era da informação: economia, sociedade e cultura. Tradução Roneide Venâncio Majer. 6. ed. São Paulo: Paz e Terra, 2002.

CCSDS - The Consultative Committee for Space Data System. Reference Model for an Open Archival Information System (OAIS). Magenta book (CCSDS 650.0M-2). Washington, DC: CCSDS, 2012. Disponível em https://public.ccsds.org/pubs/650x0m2.pdf. Acesso em: 23 out. 2021.

CONSELHO NACIONAL DE ARQUIVOS (BRASIL). Câmara Técnica de Documentos Eletrônicos. e-ARQ Brasil: Modelo de Requisitos para Sistemas Informatizados de Gestão Arquivística de Documentos. Rio de Janeiro: Arquivo Nacional, versão 2, julho 2020. Disponível em: https://www.gov.br/conara/pt- 
br/assuntos/noticias/conarq-abre-consulta-publica-visando-a-atualizacao-do-e-arqbrasil/EARQ v2 2020 final.pdf. Acesso em: 23 jul. 2021.

CONSELHO NACIONAL DE ARQUIVOS (BRASIL). Câmara Técnica de Documentos Eletrônicos. Resolução no. 43, de 4 de setembro de 2015. Estabelece diretrizes para a implementação de repositórios arquivísticos digitais confiáveis para o arquivamento e manutenção de documentos arquivísticos digitais em suas fases corrente, intermediária e permanente, dos órgãos e entidades integrantes do Sistema Nacional de Arquivos - SINAR. Disponível em: https://www.gov.br/conarg/pt-br/legislacao-arquivistica/resolucoes-doconarg/resolucao-no-43-de-04-de-setembro-de-2015. Acesso em: 23 out. 2021

CONSELHO NACIONAL DE ARQUIVOS (BRASIL). Câmara Técnica de Documentos Eletrônicos (CTDE). Glossário documentos arquivísticos digitais. 2020. Disponível em:

http://antigo.conarq.gov.br/images/ctde/Glossario/glosctde 202008 07.pdf. Acesso em: 20 jul. 2021.

DAPPERT, A. et al. Describing and preserving digital object environments. New Review of Information Networking, [s. I.], v. 18, n. 2, p. 106-173, 2013. Disponível em: https://doi.org/10.1080/13614576.2013.842494. Acesso em: 07 ago. 2021.

DAY, M. Preservation metadata. UKOLN, University of Bath, 2003. Disponível em: http://www.ukoln.ac.uk/metadata/publications/iylim-2003/. Acesso em: 07 ago. 2021.

DIGITAL PRESERVATION WORKING GROUP, UNIVERSITY LIBRARY,

GLASGOW UNIVERSITY. Glasgow University Digital Preservation Policy Version 3.8. Glasgow: [s. n.], 2020. Disponível em:

https://www.gla.ac.uk/media/Media 598622 smxx.pdf. Acesso em: 07 ago. 2021.

FENG, $\mathrm{H}$. Identity and archives: return and expansion of the social value of archives. Archival Science, v. 17, $n^{\circ}$ 2, p. 97-112, 2017.

FORMENTON, D. et al. Metadata standards as a technological resource to guarantee digital preservation. Biblios - Revista de bibliotecologia y Ciencias de la Informacion, USA, n. 68, p. 82-95, 2017. Disponível em:

https://doi.org/10.5195/biblios.2017.414. Acesso em: 07 ago. 2021.

HENTTONEN, P. Privacy as an archival problem and a solution. Archival Science, v. 17, n 3, p. 285-303, 2017. DOI: http://dx.doi.org/10.1007/s10502-017-9277-0. Acesso em: 07 ago. 2021.

KATUU, S. Managing digital records in a global environment. The Electronic Library, [s.I.], v. 34, n 5, p. 869-894, 2016, DOI: 10.1108/EL-04-2015-0064. Acesso em: 07 ago. 2021.

LAVOIE, B.; GARTNER, R. Preservation Metadata. OCLC, September 2005. Disponível em: http://www.dpconline.org/docs/reports/dpctw05-01.pdf. Acesso em: 05 ago. 2021.

LE COADIC, Y. F. A Ciência da Informação. Tradução Maria Yeda S. F. de Filgueiras Gomes. Brasília: Briquet de Lemos, 1996. 
LEVY, P. Cibercultura. São Paulo: Editora 34, 1999. Disponível em: https://mundonativodigital.files.wordpress.com/2016/03/cibercultura-pierre-levy.pdf. Acesso em: 12 ago. 2021.

LI, C.; SUGIMOTO, S. Provenance description of metadata using PROV with PREMIS for long-term use of metadata. Proceedings of the International Conference on Dublin Core and Metadata Applications. Dublin Core metadata initiative, 2014. p. 147-156. Disponível em:

https://www.scopus.com/inward/record.uri?eid=2-s2.085013660318\&partnerID=40\&md5=ca8571fafb61e76760ff385b7df0097f. Acesso em: 07 ago. 2021.

MATTERLART, A. História da sociedade da informação. Ed. Loyola: São Paulo, 2006.

MOHER, D. et al. Preferred Reporting Items for Systematic Reviews and MetaAnalyses: The PRISMA Statement. PLOS Medicine, v. 6, n. 4, p. 1-6, 2009. Disponível em:

http://journals.plos.org/plosmedicine/article/file?id=10.1371/journal.pmed.1000097\&ty pe=printable. Acesso em: 18 jul. 2021.

RAMALHO, J. C. et al. RODA-in A generic tool for the mass creation of Submission Information Packages. In: 12th Iberian Conference on Information Systems and Technologies (CISTI). Nova lorque, Estados Unidos, 2017. Disponível em: https://dx.doi.org/10.23919/CISTI.2017.7975761. Acesso em: 07 set. 2020.

RIES, T. The rationale of the born-digital dossier genetique: Digital forensics and the writing process: With examples from the Thomas Kling Archive. DIGITAL

SCHOLARSHIP IN THE HUMANITIES, ENGLAND, v. 33, n. 2, p. 391-424, 2018. Disponível em: https://doi.org/10.1093//lc/fqx049. Acesso em: 07 ago. 2021.

ROGERS, C. Diplomatics of born digital documents - considering documentary form in a digital environment. Records Management Journal, [s.I.], v. 25, n 1, p. 6-20, 2015. ISSN: 09565698, DOI: 10.1108/RMJ-03-2014-0021. Acesso em: 07 ago. 2021.

SAYÃO, L. F. Uma outra face dos metadados: informações para a gestão da preservação digital. Encontros Bibli: Revista Eletrônica de Biblioteconomia e Ciência da Informação, [S. I.], p. 1-31, 2010. Disponível em: https://doi.org/10.5007/1518-2924.2010v15n30p1. Acesso em: 07 ago. 2021.

SCHWAITZER, L. de B. da S. O arquivista na aurora digital: diálogo com Bruno Delmas. Revista do Arquivo, n. 6, p. 9-15, Abr. 2018. ISSN: 2447-908X. Disponível em:

http://www.arquivoestado.sp.gov.br/revista do arquivo/06/ensaio.php\#inicio artigo. Acesso em: 10 ago. 2021.

SPENCE, A. et al. Case study: the University of Glasgow's digital preservation journey 2017-2019. Insights, Research Information Administrator: digital preservation University, v. 32, p. 1-9, 2019. Disponível em: https://search.proquest.com/docview/2203049840?accountid=149610. Acesso em: 07 ago. 2021. 
SVÄRD, P. The woes of Swedish private archival institutions. Records Management Journal, [s.I.], v. 27, nº 3, p. 275-285, 2017. ISSN: 09565698, DOI: 10.1108/RMJ01-2016-0003. Acesso em: 13 ago. 2021. 